\title{
Molecular Epidemiology of Mycobacterium tuberculosis Isolates in 100 Patients With Tuberculosis Using Pulsed Field Gel Electrophoresis
}

\author{
Mohammad Pooideh ${ }^{1}$; Ismail Jabbarzadeh ${ }^{2}$; Reza Ranjbar ${ }^{3}$; Mahnaz Saifi ${ }^{2, *}$ \\ ${ }^{1}$ Department of Sciences, Qom Branch, Islamic Azad University, Qom, IR Iran \\ ${ }^{2}$ Mycobacteriology Department, Pasteur Institute of Iran, Tehran, IR Iran \\ ${ }^{3}$ Molecular Biology Research Center, Baqiyatallah University of Medical Sciences, Tehran, IR Iran \\ *Corresponding author: Mahnaz Saifi, Mycobacteriology Department, Pasteur Institute of Iran, Tehran, IR Iran. Tel/Fax: +98-2166968853, E-mail: mahsaifi@yahoo.com
}

Received: February 16, 2014; Revised: May 5, 2014; Accepted: May 11, 2014

\begin{abstract}
Background: Tuberculosis (TB) is a widespread infectious disease. Today, TB has created a public health crisis in the world. Genotyping of Mycobacterium tuberculosis isolates is useful for surveying the dynamics of TB infection, identifying new outbreaks, and preventing the disease. Different molecular methods for clustering of M. tuberculosis isolates have been used.

Objectives: During a one year study of genotyping, $100 \mathrm{M}$. tuberculosis isolates from patients referred to Pasteur Institute of Iran were collected and their genotyping was accomplished using pulsed field gel electrophoresis (PFGE) method.

Materials and Methods: Identification of all M. tuberculosis isolates was accomplished using standard biochemical and species-specific polymerase chain reaction (PCR) methods. Antibiotic susceptibility tests were performed using proportional method. After preparing PFGE plaques for each isolate of M. tuberculosis, Xbal restriction enzyme was applied for genome digestion. Finally, the digested DNA fragments were separated on $1 \%$ agarose gel and analyzed with GelCompar II software.

Results: Genotyping of the studied isolates in comparison with the molecular weight marker revealed two common types; pulsotype A with 71 isolates and one multidrug resistant mycobacterium (MDR) case, and pulsotype B including 29 isolates and three MDR cases. No correlation between the antibiotypes and pulsotypes was observed.

Conclusions: Molecular epidemiology studies of infectious diseases have been useful when bacterial isolates have been clustered in a period of time and in different geographical regions with variable antibiotic resistance patterns. In spite of high geographical differences and different antibiotic resistant patterns, low genetic diversity among the studied TB isolates may refer to the low rate of mutations in XbaI restriction sites in the mycobacterial genome. We also identified three MDR isolates in low-incidence pulsotype B, which could be disseminated and is highly important to consider in TB surveillance programs to prevent the spread of MDR-TB isolates in the population.
\end{abstract}

Keywords: Mycobacterium tuberculosis; Pulsed Field Gel Electrophoresis; Molecular Epidemiology

\section{Background}

Despite all medical care, Mycobacterium tuberculosis is one of the most important human pathogens and death factors known. In most countries, rapid contagion of M. tuberculosis and multidrug resistant mycobacteria (MDR), which are resistant to isoniazid and rifampin, are considered as cautions for tuberculosis (TB) controlling programs (1). In recent years, the increase in immigration rates, emerging of drug-resistant strains, and HIV co-infection with TB, especially in developing countries, have led to precise and in-time diagnosis of TB. Therefore, finding out how these are spread and transferred is of high importance $(1,2)$. For these reasons, several molecular typing methods including pulsed field gel electrophoresis (PFGE) have been taken into account for epidemiological studying of TB.

The classification of M. tuberculosis isolates is essential for taking the spread of TB under control. Phenotypic methods such as phage-typing have been applied to separate mycobacterial species, but they have not been useful in molecular epidemiology studies. Molecular techniques based on bacterial genome have been more practical in genotyping studies of mycobacterial isolates (3). In PFGE, the whole bacterial genome is used for enzymatic digestion and finding clonal similarities, which provides us useful information on controlling the spread of the disease (4). In some cases, using PFGE genotyping method for genetic relatedness of mycobacterial isolates has more advantages than IS6110-restriction fragment length polymorphism (RFLP), because the last method depends on the copy number of the IS6110 sequence in the isolates and it is not effective for isolates with less than six IS6110 copies in their genomes. On the other hand, PFGE method does not have this limitation and using the entire genome of the organisms instead of focusing on short repeated elements is more beneficial $(5,6)$.

In PFEG, the intact bacterial genome is digested by spe-

Copyright (C) 2015, Ahvaz Jundishapur University of Medical Sciences. This is an open-access article distributed under the terms of the Creative Commons Attribution-NonCommercial 4.0 International License(http://creativecommons.org/licenses/by-nc/4.0/) which permits copy and redistribute the material just in noncommercial usages, provided the original work is properly cited. 
cial restriction enzymes. Having been given the fragment patterns and genetic diversity of the strains, we could have a standard and powerful instrument to genotype the $M$. tuberculosis isolates $(4,6)$. The resultant information on the analysis of this method is practical for monitoring the characteristics of available isolates, representing strain similarities in an area, detecting contamination resources, and designing programs to control pathogenic factors. Several restriction enzymes including XbaI, AseI, DraI, SpeI were used in PFEG method to digest TB bacterial genomes. XbaI enzyme recognizes less than 10 digestion sites per $106 \mathrm{bp}$ in average and digests $40-50 \mathrm{~kb}$ DNA pieces which are not supportable and moveable by common gel electrophoresis, whereas in PFEG, the digested genome is separated easily by alternative changes in the electrical field $(3,4)$.

\section{Objectives}

Application of TB genotyping in a surveillance program is highly important. The present study was conducted to monitor the genetic diversities of $M$. tuberculosis isolated from patients in the Mycobacteriology Department of Pasteur Institute in, Tehran, Iran, during 2010 - 2011.

\section{Materials and Methods}

\subsection{Bacterial Isolation and Identification}

Comprehensive information of 100 patients referred to the Mycobacteriology Department of Pasteur Institute was gathered during 2010 - 2011. The information on gender, age, nationality, HIV infection and close contact with infected or carrier people were questioned. Direct smears of all the samples were stained by Ziehl-Neelsen technique to show acid-fast bacilli existence. After decontamination by N-acetyl-L-cysteine-sodium hydroxide, the samples were cultured in Lowenstein-Jensen agar and incubated in $37^{\circ} \mathrm{C}$ for two months and the growth results were monitored (7). All the positive cultures that were suspicious to $M$. tuberculosis were tested by several standard methods including niacin test, catalase activity $\left(22^{\circ} \mathrm{C}\right.$ and $\left.68^{\circ} \mathrm{C}\right)$, nitrate reduction, thiophen-2-carboxylic acid hydrazide (TCH) sensitivity and pigment production (7).

\subsection{Antibiotic Sensitivity Tests}

The antibiotic sensitivity tests of $M$. tuberculosis isolates to rifampin (Sigma, USA) $(40 \mu \mathrm{g} / \mathrm{mL})$, isoniazid (Sigma, USA) (0.2 $\mu \mathrm{g} / \mathrm{mL})$, ethambutol (Sigma, USA) $(2 \mu \mathrm{g} / \mathrm{mL})$, kanamycin (Sigma, USA) $(20 \mu \mathrm{g} / \mathrm{mL}$ ), streptomycin (Sigma, USA) $(4 \mu \mathrm{g} / \mathrm{mL})$ and ethionamide (Sigma, USA) $(20 \mu \mathrm{g} / \mathrm{mL})$ were determined by proportional method using standard guidelines (8).

\subsection{Genus and Species Polymerase Chain Reaction}

All 100 M. tuberculosis isolates that were confirmed by genus and species PCR reactions were analyzed. Chro- mosomal DNA of all M. tuberculosis isolates was extracted using a silica gel column system high pure PCR template preparation kit (Roche, Germany). The extracted DNA samples were electrophoresed on $0.8 \%$ agarose gel and stained by ethidium bromide. The separated DNA bands were studied under the light of UV transilluminator. PCR reaction with specific primers in the following measurements with a total volume of $25 \mu \mathrm{L}$ was performed to confirm M. tuberculosis isolates. The primer sequences were $\mathrm{F}$ : 5'ATGCGGGCGTTGATCATCGTC-3' and R: 5'-CGGTGTGCCGGAGAAGCGC-3'. The PCR mixture included $2.5 \mu \mathrm{L}$ PCR 10x buffer, $1.5 \mathrm{mM} \mathrm{MgCl}_{2}, 200 \mu \mathrm{M}$ dNTPs $=30$ pmol primer-F, 30 pmol primer-R, 2 unit Taq DNA polymerase and $5 \mu \mathrm{L}$ DNA. The amplification was accomplished in $95^{\circ} \mathrm{C}$ for 12 minutes, 35 cycles in $94^{\circ} \mathrm{C}$ for one minute, $64^{\circ} \mathrm{C}$ for one minute, $72^{\circ} \mathrm{C}$ for one minute, and final extension in $72^{\circ} \mathrm{C}$ for five minutes (9). The amplified $185 \mathrm{bp}$ fragments were assessed by electrophoresis on $1.5 \%$ agarose gel and in 80 $\mathrm{V}$ for about one hour and stained by ethidium bromide.

\subsection{Pulsed Field Gel Electrophoresis}

Loop full colonies of $100 \mathrm{M}$. tuberculosis isolates with confirmed results in species identification with PCR were taken and inactivated in $200 \mu \mathrm{L}$ distilled water in $80^{\circ} \mathrm{C}$ for an hour. They were centrifuged in $4000 \mathrm{rmp}$ for $15 \mathrm{~min}$ utes, their sediments were rewashed by $1.5 \mathrm{~mL}$ Tris-EDTA (TE) buffer and solved in $1.5 \mathrm{~mL}$ TE buffer $(10,11)$. Afterwards, an equal volume of the given bacterial suspension was mixed with $1.5 \%$ InCert agarose and $10 \mu$ L lysozyme (10 $\mathrm{mg} / \mathrm{mL}$ ) (Sigma, USA) and poured in two molds. Two prepared plaques were incubated in $1.5 \mathrm{~mL}$ lysis buffer (containing $150 \mu \mathrm{L}$ lysozyme, $1.5 \mathrm{~mL}$ TE buffer and $5 \mu \mathrm{L}$ RNase A) in $37^{\circ} \mathrm{C}$ for 24 hours. To eliminate proteins, the mixtures were incubated in $1.5 \mathrm{~mL}$ ESP buffer (0.5 mM EDTA, $1.5 \mathrm{~mL}$ sarcosil $10 \%, 1 \mathrm{mg} / \mathrm{mL}$ proteinase $\mathrm{K}$ ) (Sigma, USA) in $55^{\circ} \mathrm{C}$ for 48 hours. Finally, they were washed five times with TE buffer to be prepared for enzymatic digestion (11).

At the pre-digestion stage, the prepared plaques were washed twice in deionized water and were incubated by $100 \mu \mathrm{L}$ enzymatic buffer at room temperature for an hour. Half of each agarose plaque was incubated with $100 \mu \mathrm{L}$ enzymatic buffer and $6 \mu \mathrm{L} \mathrm{XbaI} \mathrm{(Roche,} \mathrm{Germany)} \mathrm{in} 37^{\circ} \mathrm{C}$ for 24 hours. To perform PFGE, CHEF-DR III apparatus was programmed to replace electric fields per 0.5 to 10 seconds in 16 hours at the first switch time and per 10 to 17 seconds in four hours at the second switch time to move the digested DNA bands. The device temperatures, voltages and field angles were set at $14^{\circ} \mathrm{C}, 6 \mathrm{~V} / \mathrm{cm}^{2}$ and $120^{\circ} \mathrm{C}$, respectively $(5$, 6). Agarose gel was stained by ethidium bromide and monitored by a transilluminator device. Finally, PFGE patterns were analyzed by GelCompar II software.

\section{Results}

A total of 100 clinical M. tuberculosis isolates were isolated from 46 females and 54 males, aged five months to 86 years old, attending the Mycobacteriology Department 
of Pasteur institute of Iran. All the patients were Iranian except one Afghan man and they all lived in cities. Out of all the patients, $42 \%$ had positive direct smears.

\subsection{Antibiotic Sensitivity Tests}

The frequencies of resistance to ethionamide, streptomycin, ethambutol, rifampin, kanamycin and isoniazid were $61 \%, 37 \%, 26 \%, 23 \%, 21 \%$, and $13 \%$, respectively. Totally $71 \%$ of the samples were resistant to at least one drug, and four MDR isolates were detected.

\subsection{Species-Specific Polymerase Chain Reaction}

The result of the PCR reaction was considered positive, when $185 \mathrm{bp}$ fragments were observed among all the studied isolates of M. tuberculosis (Figure 1).

\subsection{Pulsed Field Gel Electrophoresis}

Digestion patterns of the isolates were analyzed by GelCompar II software in comparison with Salmonella choleraesuis serotype Braenderup H9812 as the molecular weight marker (Figure 2). The given dendrogram of genetic similarities represented two common types (Figure 3); common type A (pulsotype A) was the most prevalent one comprising 71 isolates and common type B (pulsotype B) included the other 29 isolates.

\section{Discussion}

TB is a chronic infectious disease caused by M. tuberculosis (7). Before using molecular typing researches, it was hard to detect the infection resource. As M. tuberculosis gets transferred by aerosol particles by infected respiratory secretions, it would remain a hidden infection without any noticeable sign $(5,7)$. Another significant point taken into account is the role of intercity immigration in transferring TB. It is most likely that the disease spreads in highly populated areas when people commute between workplace and home in suburban areas while they are infected by TB, being considered as carriers (1). The results extracted from our studied patients' demographic questionnaires showed that approximately $90 \%$ of patients commute in Tehran and its suburbs such as Karaj, Shahriar, Shahr-e-Ray, Islamshar, and Robat-Karim. Therefore, controlling the TB infection through human travel is highly important in preventing the spread of TB. In a study by Asgharzadeh et al. (12), among 100 patients, 71 were sensitive to streptomycin, ethambutol, isoniazid, rifampicin, and their resistance to streptomycin, isoniazid and rifampicin were 15.2, 9.5, and 5.7\%, respectively. Our recent research in comparison showed a rise-up in the number of drug-resistant and MDR isolates, which explains the necessity of using rapid recognition of MDR strains and controlling the transference of the disease. Using molecular methods to represent the spread of $M$. tuberculosis isolates that show resistance to drugs is important. Moreover, simultaneous application of molecular techniques and the results of antibiotic re- sistance test is a precise and rapid method to prevent the spread of different types of M. tuberculosis isolates $(10,13)$. Distinguishing phenotypic and genotypic similarities to recognize how a disease spreads in an area, understanding its pathogenic agents and the cure of the disease are extremely important factors $(10,14)$.

Phenotypic characters may change under special circumstances such as place and time. Hence, studying the bacteria according to given information from genomic DNA is recommended to acquire reliable and clear data $(14,15)$. We applied PFGE to represent genetic diversities of $M$. tuberculosis isolates. Comparison of the restriction patterns of $100 \mathrm{M}$. tuberculosis isolates with XbaI restriction enzyme revealed only two common pulsotypes. Both types mostly occurred in Tehran and its suburbs which can rapidly be disseminated and must be considered to control this infection. The high incidence of MDR isolates (75\%) in common type B should be under closer inspection during surveillance programs to prevent the spread of MDR-TB in future.

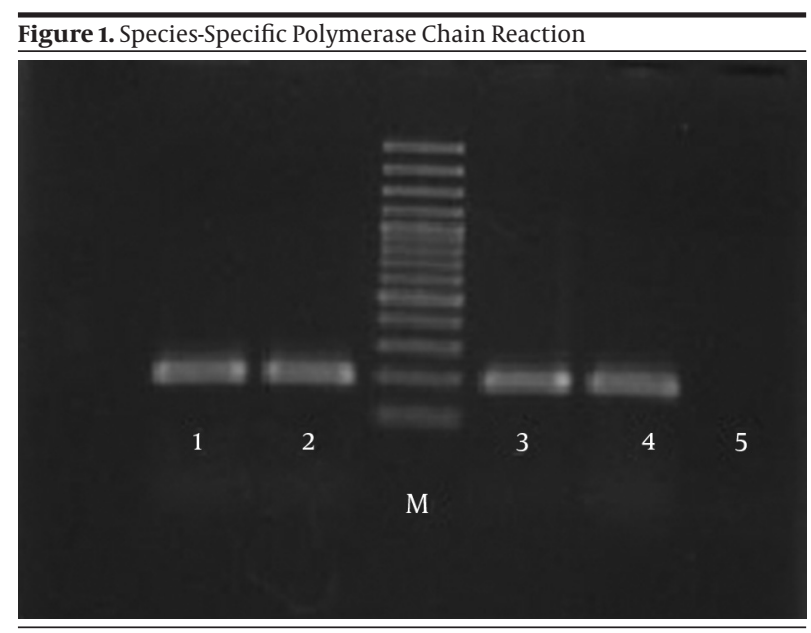

Lanes 1, 2, 3, and 4,185 bp fragments; M, molecular weight marker; 5, negative control.

Figure 2. Pulsed Field Gel Electrophoresis Patterns of Mycobacterium tuberculosis Isolates

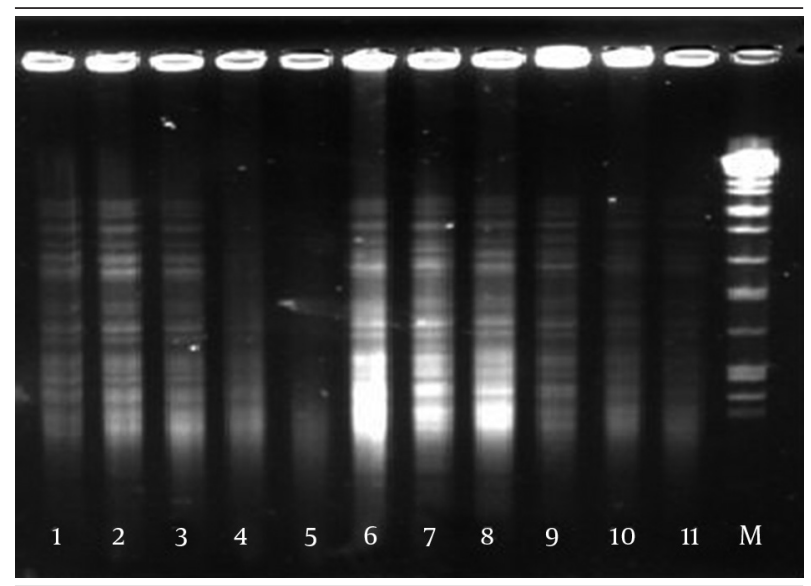

Lanes 1, 2,3, 4, 5, 6, 7, 8, 9, 10, and 11, M. tuberculosis isolates; Lane 12, molecular weight marker. 


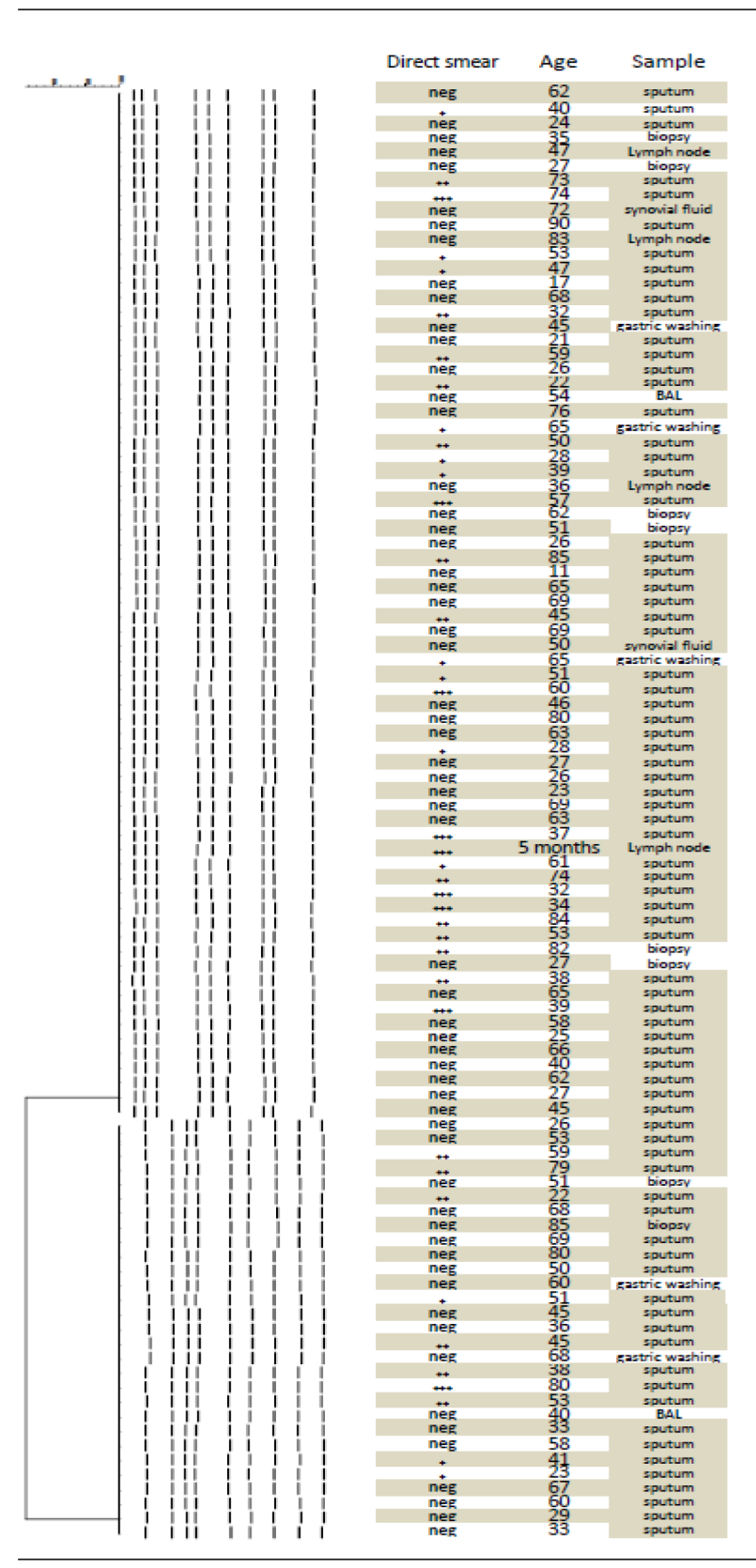

Figure 3. Dendrogram of Mycobacterium tuberculosis Isolates

The limited patterns of DNA fragments from enzymatic digestion showed that restricted sites of $\mathrm{XbaI}$ were protected in studied M. tuberculosis isolates. Zhang et al. (5), showed that XbaI and SpeI were more powerful in distinguishing M. tuberculosis isolates than AseI, DraI. On the other hand, similar to the study by Feizabadi et al. (10), reporting that DraI created more polymorphism than XbaI, the low genetic diversity among our studied isolates may have been caused by the presence of the conserved area and the absence of mutations on the mycobacterial DNA for Xbal restriction sites. In molecular epidemiology studies of infectious disease, applying different molecular typing methods increases the discrimination power and provides more information about the studied population up to 21 - 35\% $(16,17)$. Therefore, controlling the TB infection through monitoring the incoming travelers is necessary.

\section{Acknowledgements}

This research was conducted in Tehran Pasture Institute, Mycobacteriology Department, with co-operation of Islamic Azad University, Faculty of Sciences, Qom branch. We also appreciate Mrs. Ahmadi for her gracious assistance regarding the usage of CHEF-DR3 apparatus in Molecular Biology Research Center, Baqiyatallah University, Tehran, Iran.

\section{Authors' Contributions}

Mahnaz Saifi: study concept and design, analysis and interpretation of data and final revision of the manuscript; Ismail Jabbarzadeh: research advisor and data analysis; Mohammad Pooideh: administrative, technical and material support, drafting of the manuscript; Reza Ranjbar, contribution for the CHEF DRIII PFGE apparatus.

\section{Funding/Support}

This study was supported by a research grant No. 521 from Pasteur Institutes of Iran and did not receive any other financial support.

\section{References}

1. Baptista IM, Oelemann MC, Opromolla DV, Suffys PN. Drug resistance and genotypes of strains of Mycobacterium tuberculosis isolated from human immunodeficiency virus-infected and non-infected tuberculosis patients in Bauru, Sao Paulo, Brazil. Mem Inst Oswaldo Cruz. 2002;97(8):1147-52.

2. Shafer RW, Singh SP, Larkin C, Small PM. Exogenous reinfection with multidrug-resistant Mycobacterium tuberculosis in an immunocompetent patient. Tuber Lung Dis. 1995;76(6):575-7.

3. Hughes VM, Stevenson K, Sharp JM. Improved preparation of high molecular weight DNA for pulsed-field gel electrophoresis from mycobacteria. J Microbiol Methods. 2001;44(3):209-15.

4. Olson ES, Forbes KJ, Watt B, Pennington TH. Population genetics of Mycobacterium tuberculosis complex in Scotland analysed by pulsed-field gel electrophoresis. Epidemiol Infect. 1995;114(1):153-60.

5. Zhang Y, Mazurek GH, Cave MD, Eisenach KD, Pang Y, Murphy DT, et al. DNA polymorphisms in strains of Mycobacterium tuberculosis analyzed by pulsed-field gel electrophoresis: a tool for epidemiology. JClin Microbiol.1992;30(6):1551-6.

6. Birren B, Lai E. Preparation of DNA for pulsed field analysis. In: Lai BB editor. Pulsed Field Gel Electrophoresis.. San Diego: Academic Press; 1993. pp. 25-74.

7. Dunlap NE, Bass J, Fujiwara P et al. Diagnostic standards and clas sifi- cation of TB in adults and children. Am J Respir Crit Care Med 2000; 161: 1376-1395.

8. Clinical and Laboratory Standards Institute. Susceptibility Testing of Mycobacteria, Nocardia, and Other Aerobic Actinomycetes.Wayne: Clinical and Laboratory Standards Institute; 2011.

9. Bannalikar AS, Verma R. Detection of Mycobacterium avium \& M tuberculosis from human sputum cultures by PCR-RFLP analysis of hsp65 gene \& pncA PCR. Indian J Med Res. 2006;123(2):165-72.

10. Feizabadi MM, Robertson ID, Edwards R, Cousins DV, Hampson DJ. Genetic differentiation of Australian isolates of Mycobacterium tuberculosis by pulsed-field gel electrophoresis. J Med Microbiol.1997;46(6):501-5.

11. Charvin M, Rastogi N, Lévy-Frébault VV. An easy and rapid method for isolation of entire mycobacterial genome for ap- 


\section{Pooideh M et al.}

plication in pulsed-field gel electrophoresis. Current Microbiol. 1991;22(5):327-31.

12. Asgharzadeh M, Kafil HS, Roudsary AA, Hanifi GR. Tuberculosis transmission in Northwest of Iran: using MIRU-VNTR, ETR-VNTR and IS6110-RFLP methods. Infect Genet Evol. 2011;11(1):124-31.

13. Asgharzadeh M, Shahbabian K, Majidi J, Aghazadeh AM, Amini $\mathrm{C}$, Jahantabi AR, et al. IS6110 restriction fragment length polymorphism typing of Mycobacterium tuberculosis isolates from East Azerbaijan Province of Iran. Mem Inst Oswaldo Cruz. 2006;101(5):517-21.

14. Allardet-Servent A, Bouziges N, Carles-Nurit MJ, Bourg G, Gouby A, Ramuz M. Use of low-frequency-cleavage restriction endonucleases for DNA analysis in epidemiological investi- gations of nosocomial bacterial infections. J Clin Microbiol. 1989;27(9):2057-61.

15. Singh SP, Salamon H, Lahti CJ, Farid-Moyer M, Small PM. Use of pulsed-field gel electrophoresis for molecular epidemiologic and population genetic studies of Mycobacterium tuberculosis. J Clin Microbiol. 1999;37(6):1927-31.

16. Silbert S, Boyken L, Hollis RJ, Pfaller MA. Improving typeability of multiple bacterial species using pulsed-field gel electrophoresis and thiourea. Diagn Microbiol Infect Dis. 2003;47(4):619-21.

17. Goyal M, Saunders NA, van Embden JD, Young DB, Shaw RJ. Differentiation of Mycobacterium tuberculosis isolates by spoligotyping and IS6110 restriction fragment length polymorphism. J Clin Microbiol.1997;35(3):647-51. 